\title{
Effects of ABA on Physiological Characteristics of Tomato under Waterlogging
}

\author{
Wei Gao ${ }^{1 *}$, Dongmei Yin ${ }^{1}$, and Zhuqing $\operatorname{Han}^{1}$ \\ ${ }^{1}$ College of Ecology, Shanghai Institute of Technology, Shanghai 201418, China
}

\begin{abstract}
The effects of waterlogging on antioxidant enzyme activities responses in five different lines, i.e. ABA-deficient mutant (0673) and its control (0535), two ABA over-production transgenic rd29A:NCED1 lines (\#2, \#7) and Mill. L. cv. New Yorker (WT) were investigated. The waterlogging was mimicked by treating pot plants with flooding. The malondialdehyde (MDA) content, superoxide dismutase (SOD), peroxidase (POD) and catalase (CAT) activity in the leaves were evaluated in all treatments. The results showed that after 7 days waterlogging treatment, the malondialdehyde (MDA) was increased in all plants, especially in LA0673. Compared with the LA0673, \#2 and \#7 significantly increase the activities of SOD, POD and CAT under waterlogging stress. Therefore, ABA could improve the waterlogging tolerance of tomato by increasing the activities of antioxidant enzymes under waterlogging stress.
\end{abstract}

\section{Introduction}

In the life history of plants, they are inevitably threatened by environmental, such as waterlogging, salt, drought, extreme temperature stress and so on. With the deterioration of the global environment, the uneven distribution of rainfall leads to the frequent occurrence of disasters such as heavy rains and floods in several regions[1]. Soil waterlogging disrupts the water balance in plants, leading to oxygen restriction in plant roots[2]. As waterlogging stress intensifies, hypoxia causes root systems to eventually rot, over ground parts to wilt, even resulted in death of plants[3].Tomato (Lycopersicon esculentum Mill.) is a herbacary plant of Solanaceae and Solanum, native to South America, and now widely distributed in China, it is cultivated all over the north and south. Tomato have high economic benefit in horticultural crops. Studies on diseases have shown that eating more tomatoes, related product can effectively reduce the risk of cancer, cardiovascular and cerebrovascular diseases and other chronic diseases[4-6].

Abscisic acid (ABA) is an important plant phytohormone and plays a key role in the regulation of seed development, dormancy, and germination, plant growth and flowering inhibition, and abiotic stress response pathways. ABA also interacts with other plant hormones, such as auxin and ethylene, to precisely regulate root growth, including that of preprimary roots, lateral roots, and root hairs . Over millions of years of evolution, plants have developed antioxidant systems including antioxidant enzymes (SOD, CAT, POD, etc.).And substances that defend against or reduce the toxic effects of reactive oxygen species and free radicals caused by abiotic stress[7, 8]. In normal plant cells, the ROS production and defense system maintain a dynamic balance, which may be disturbed by water stress, leading to an increase in ROS production in wheat cells and eventually the activation of PCD[9].

At present, there are many studies on waterlogging tolerance of vegetables at home and abroad, and there are also many studies on ABA, but there are still few studies on the stress resistance of ABA to tomato. In this study, we exposed seedlings of the ABA-deficient mutant LA0673 and its control LA0535, and two ABAover production transgenic $r d 29 A$ :NCED1 lines and their WT Mill. L. cv. New Yorker to waterlogging for up to seven days and recorded the changes in activities of antioxidant enzymes, so as to provide some theoretical reference for the follow-up study of waterlogging tolerance of tomato and the popularization and utilization of tomato.

\section{Materials and methods}

\subsection{Plant materials and grow conditions}

Tomato seeds of the ABA-deficient mutant (LA0673) and its control (LA0535) were obtained from the C.M. Rick Tomato Genetics Resource center (University of California, Davis). Two transgenic rd29A:NCED1 lines $(\# 2, \# 7)$ that over-produce ABA in WT Mill. L. cv. New Yorker background have been described previously[10]. LA0673 is defective for maturation of ABA-aldehyde oxidase Mo cofactor in ABA biosynthesis and has reduced ABA levels, while rd29A:NCED1 lines display increased ABA levels contributed by enhancing 9-cisepoxycarotenoid dioxygenase (NCED) expression, which is a crucial enzyme in ABA biosynthesis 
controlled by the stress promoter rd29A. The sterilized seeds were seeded and germinated on a solid MS medium. The condition of growth is to maintain a constant temperature of $22{ }^{\circ} \mathrm{C}$ in a chamber with a light intensity of $40 \mu \mathrm{mol} / \mathrm{m} 2 / \mathrm{s}$. After two true leaves grew out, seedlings were carefully transferred into pots containing the same amounts of UC Mix (1/3 peat, 1/3 sand, $1 / 3$ redwood compost), and planted in the botanical garden of Shanghai Institute of Technology under natural conditions without supplemental lights at 25-30 ${ }^{\circ} \mathrm{C}$.

The experiment was proceeded as a completely randomized block with three biological replicates. Plants were grown in UC mix soils in greenhouse for 60 days under non-stress conditions. Then plants were subjected to waterlogging at $10 \mathrm{~cm}$ above the water surface for $0 \mathrm{~d}$, 1d, 2d, 4d and $7 \mathrm{~d}$ and observed sampled for determination.

\subsection{Measurement of MDA content}

The degree of lipid peroxidation was determined by measuring the MDA content according to the method of thiobarbituric acid with slight modification[11] Malondialdehyde was measured by thiobarbituric acid (TBA) method. 0.5g fresh leaf sample was homogenized in $5 \mathrm{~mL} 5 \%$ trichloroacetic acid (TCA) and the homogenate was centrifuged at $4000 \mathrm{rpm}$ for $10 \mathrm{~min}$. The $2 \mathrm{~mL}$ supernatant mixed with $2 \mathrm{~mL}$ of $0.6 \%$ TBA was heated to $95^{\circ} \mathrm{C}$ for $30 \mathrm{~min}$, cooled on ice quickly and then the reaction mixture was centrifuged at $3000 \mathrm{rpm}$ for $15 \mathrm{~min}$. The extract was measured at 450, 532 and $600 \mathrm{~nm}$ using ultraviolet spectrophotometer to calculate its absorbance.

\subsection{Antioxidant enzymes activities}

The extraction of enzyme was harvested by homogenizing $0.5 \mathrm{~g}$ of fresh leaf with $5 \mathrm{~mL}$ phosphate buffer solution $(50 \mathrm{mM}, \mathrm{pH} 7.8)$ containing Na2HPO4, $\mathrm{KH}_{2} \mathrm{PO}_{4}$. The homogenate was centrifuged at 12,000 rpm for $15 \mathrm{~min}$ at $4^{\circ} \mathrm{C}$. The supernatant was saved at $4^{\circ} \mathrm{C}$ until used for SOD, POD, CAT activity assays.

The method of Giannopolitis and Ries[12]was employed to determine SOD activity. The $4 \mathrm{~mL}$ reaction solution for SOD activity contained $2.3 \mathrm{~mL}$ phosphate buffer (50mM, pH7.8), 0.4mL L-methionine (130mM), $0.4 \mathrm{~mL}$ NBT, $0.4 \mathrm{~mL}$ EDTA-Na2 $(100 \mu \mathrm{M}), 0.4 \mathrm{~mL}$ riboflavin $(20 \mu \mathrm{M})$ and $0.1 \mathrm{~mL}$ leaf extract. SOD activity was measured by the photochemical nitro-blue tetrazolium method. The assay mixture was illuminated for $30 \mathrm{~min}$ under the 40001x light and the absorbance was recorded at $560 \mathrm{~nm}$ ultraviolet-visible spectrophotometer. One unit of SOD activity was described as the sum of enzyme, which was used for inhibiting the photochemical reduction of NBT by $50 \%$

Guaiacol method was used to measure POD activity[13]. The $3 \mathrm{~mL}$ assay mixture for APX activity contained $50 \mathrm{mmol} / \mathrm{L}$ phosphate buffer $100 \mathrm{~mL}$, Guaiacol $28 \mathrm{~L}+30 \% \mathrm{H}_{2} \mathrm{O}_{2} 19 \mu \mathrm{M}$ and $2 \mathrm{~mL}$ enzyme extract. POD activity was calculated by the changes of absorbance at 470nm for $1 \mathrm{~min}$. One unit of POD activity was expressed as the sum of enzyme that caused $1 \mathrm{mmol}$ AsA oxidate per min.

CAT activity was determined by ultraviolet spectrophotometry [14]. The $3 \mathrm{~mL}$ reaction mixture for CAT activity contained $1.5 \mathrm{~mL}$ phosphate buffer $(50 \mathrm{mM}$, $\mathrm{pH} 7.8), \quad 1 \mathrm{~mL} \mathrm{H}_{2} \mathrm{O}, 0.3 \mathrm{~mL} \quad 0.1 \mathrm{M} \mathrm{H}_{2} \mathrm{O}_{2}$ and $0.2 \mathrm{~mL}$ enzyme extract. CAT activity was determined by monitoring the rate of $\mathrm{H}_{2} \mathrm{O}_{2}$ consumption at $240 \mathrm{~nm}$ for 4 min. One unit of CAT activity was defined as the sum of enzyme used for degrading $1 \mathrm{mmol} \mathrm{H}_{2} \mathrm{O}_{2}$ into $\mathrm{H}_{2} \mathrm{O}$ per $\min$.

\subsection{Statistical analysis}

All experiments in this study were repeated three times in independent experiments. Data were expressed as the mean \pm standard deviation. The statistical analysis was performed using SPSS 22.0 software. The values were evaluated by $t$ test and one-way analysis of variance (ANOVA) followed by Duncan's multiple range tests. Different small letters and capital letters expressed on data indicate significantly different at the 0.05 and 0.01 levels.

*Expressed on data indicate significantly different at the 0.05 level.

\section{Results}

\subsection{Statistical analysis}

Malondialdehyde, which is the final product of lipid peroxidation, the content of MDA in cells reflects the level of formation damage induced by lipid peroxidation, and it can also be used to judge the degree of plant environment stress response [15].

Under waterlogging stress, the content of MDA rosed and then drop in the leaves of five different tomato lines (Fig.1). After 4 days of waterlogging stress, contents of MDA in ABA-deficient mutant LA0673 were significantly higher than the other four lines, increased by $29.08,117.34,103.51$, and $106.42 \%$ respectively. After 7 days of waterlogging stress, MDA coment was higher than the control in all lines, especially in LA0673 and LA0535, increased by 283.64 and $107.18 \%$, respectively (Fig. 1). 


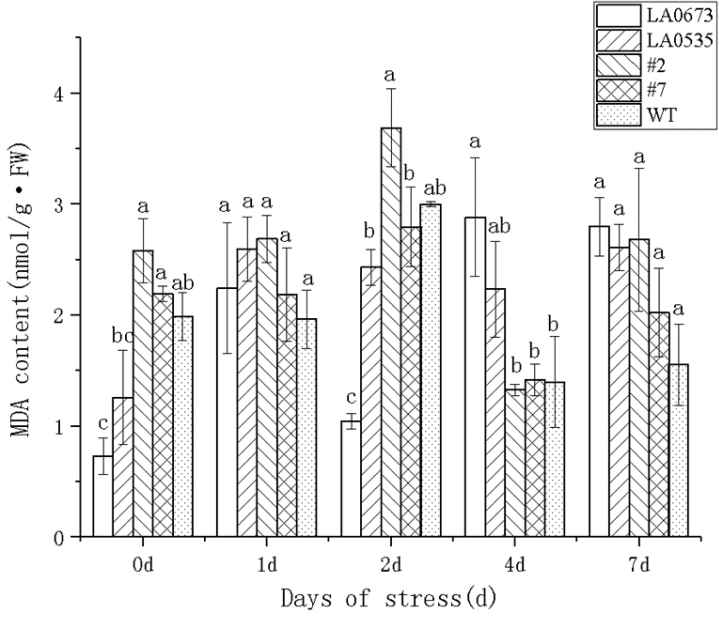

Fig. 1. Effects of ABA on the MDA content of tomato in response to waterlogging

The MDA content of ABA-deficient mutant and control, ABA-overproduction lines and WT tomato plants under nonstress or stress conditions. Plants were grown in UC mix soils in greenhouse for 60 days under non-stress conditions. Then plants were subjected to waterlogging at $10 \mathrm{~cm}$ above the water surface for $0 \mathrm{~d}, 1 \mathrm{~d}, 2 \mathrm{~d}, 4 \mathrm{~d}$ and $7 \mathrm{~d}$. The data were expressed as mean \pm standard error (SE.) from three biological replicates. Different letters denote statistical significance using Duncan's multiple range test at $\mathrm{P}<0.05$.

\subsection{Activities of SOD, POD, CAT in leaves}

A large amount of reactive oxygen species would be generated in plants under various environmental stresses. $\mathrm{SOD}$, the first antioxidant enzyme discovered in plants, can disproportionate superoxide anion to $\mathrm{H}_{2} \mathrm{O}_{2}$ and O2timely and effectively, and plays an important role in environment adaptation of plants[16]. Catalase and peroxidase are two ubiquitous antioxidant enzymes in plants, react quickly to the accumulation of intracellular $\mathrm{H}_{2} \mathrm{O}_{2}$, and catalyze the decomposition of $\mathrm{H}_{2} \mathrm{O}_{2}$ to waterand oxygen [15]. The synergy of all antioxidant enzymes could improve plants tolerance to biotic and abiotic stresses.

Comparing to control groups, SOD activity in five lines showed a trend of decrease first and then increase (Fig.2A). After 4 days of waterlogging, activities of SOD at different flowering days were increased. At 7 days, SOD activity of $\# 2$ reached the highest value.

As shown in Fig.2B, the effect of waterlogging stress on POD activity of all lines were dropped and then rose during the treatment period. At 2 days, activities of POD were increased significantly in \#2, increased by $104.98 \%$ (Fig. 2B). At 7 days, POD activity in LA0673 was lower significantly compared the other lines. After waterlogging treatment, CAT activity of all lines showed a trend of decreasing first and then increasing (Fig. 2C).
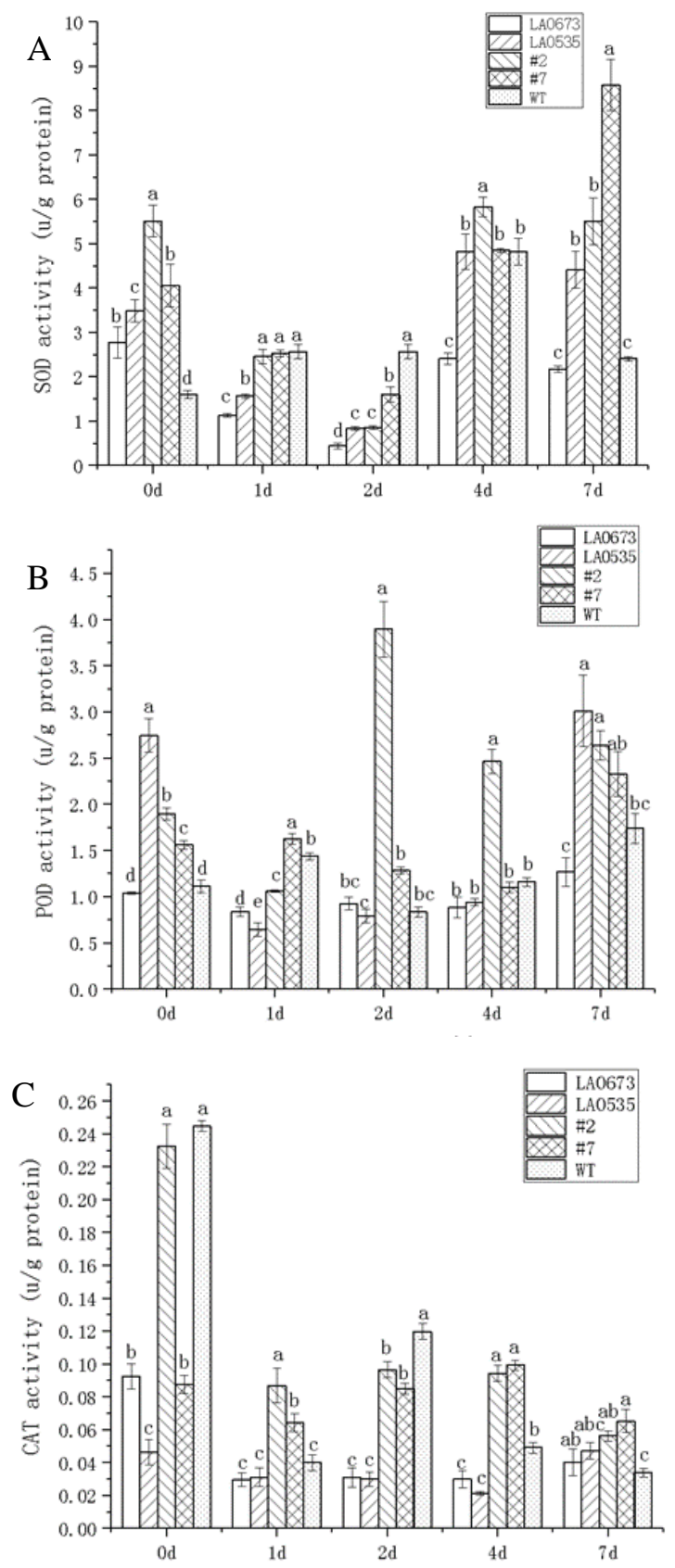

Fig. 2. Effects of $A B A$ on the antioxidant enzymes activity of $\mathrm{A}$ : SOD, B :POD, $\mathrm{C}: \mathrm{CAT}$ in response to waterlogging

Effects of waterlogging on the antioxidant enzymes activity of (A) POD, (B) CAT, (C) SOD in phenotypes of ABAdeficient mutant and control, ABA-overproduction lines and WT tomato plants. Plants were grown in UC mix soils in greenhouse for 60 days under non-stress conditions. Then plants were subjected to waterlogging at $10 \mathrm{~cm}$ above the water surface for $0 \mathrm{~d}, 1 \mathrm{~d}, 2 \mathrm{~d}, 4 \mathrm{~d}$ and $7 \mathrm{~d}$. The values are means \pm standard deviation of three replications. Different Lowe case letters represent significant differences based on Duncan's multiple in comparisons between WT, \#7, \#2, LA0673 and LA0535 all under waterlogging, at $\mathrm{P}<0.05$, respectively.

\section{Results}

China has a vast territory and there are great different between regions in the natural environment[17]. Waterlogging changes the morphology of plants obviously, 
inhibits plant growth and decreases biomass. As we known, MDA in cells could inactivate many functional proteins by combining with them on the cytomembrane, then destroyed the biological structure and function of cells, and finally influenced metabolic function of cells [18].Water-logging gives rise to the loss of oxygen in the roots of plants, which causes a series of physiological and biochemical reactions, and leads to the increasing of MDA content in plant leaves, and the cytomembrane structure would be broken, along with the increasing of membrane permeability. The longer the time of waterlogging treatment was, the more MDA accumulated in plants [19].

SOD, POD and CAT are important enzymatic protection system in plants, which can scavenge reactive oxygen species effectively by enzymatic reaction. The activity of SOD could be stimulated in plants under waterlogging stress and thus reduced the damage caused by ROS, and the activity of antioxidant enzymes was positively correlated with the antioxidant capacity of plants under waterlogging [20]. It is very essential to control the production of ROS within the appropriate range, otherwise it will damage the cell membrance, causing the death of cells and affect plant growth [21]. Improving antioxidant enzyme activities, such as activities of superoxide dismutase (SOD), catalase (CAT) and ascorbate peroxidase (APX), becomes an effective way to resist oxidative stress [22-24].

In this study, we measured malondialdehy (MDA) content, activities of superoxide dismutase (SOD), peroxidase (POD) and catalase (CAT) under waterlogging stress, in order to better understand the waterlogging stress responses of tomato. Compared with the ABA-deficient mutant LA0673, ABA-overproduction lines $(\# 2, \# 7)$ could significantly increase the activities of SOD, POD and CAT under waterlogging stress, while significantly reduce the contents of MDA. Indicating that ABA could effectively reduce the accumulation of reactive oxygen species, reduce the damage of reactive oxygen species and improve the waterlogging tolerance of tomato by increasing the activities of antioxidant enzymes under waterlogging stress.It can be concluded that ABA plays an important role in improving the resistance of tomato to waterlogging stress, and the physiological and molecular mechanism of this action needs to be further studied.

\section{Conclusion}

The responses of the ABA-deficient mutant (LA0673), control (LA0535), ABA-overproduction lines (\#2, \#7), and has a vast territory and there are great different between regions the control WT Mill. L. cv. New Yorker tomato plants were diverse to waterlogging treatment. It provides a good guide for subsequent studies on ABAdependent or independent regulation mechanism of tomato by waterlogging.
Of course, effects of ABA on molecular mechanism should be further investigated to elucidate the adaptive diversity of five tomato lines to waterlogging.

\section{References}

1. Y.H. Lee, K.S. Kim, Y.S. Jang, J.H. Hwang, D.H. Lee, I.H. Choi, Plant Cell Reports 33, 289299(2014)

2. M.P. Bange, B.J. Atwell, U. Najeeb, D. Tan. Journal of Agronomy \& Crop Science/zeitschrift Fur Acker Und Pflanzenbau, (2016)

3. R.E. Shaw, W.S. Meyer, A, S.D. Mcneill. Tyerman, Crop \& Pasture Science 64, 549(2013)

4. M. Dorais, D.L. Ehret, A.P. Papadopoulos, Phytochemistry Reviews 7, 231-250(2008)

5. Edward, Giovannucci, Jnci J Natl Cancer Inst, (1999)

6. H.D. Sesso, S. Liu, G.J. Michael, J.E. Buring,Journal of Nutrition, 7(2003)

7. B.S. Haddadi, H. Hassanpour, V. Niknam,Acta Physiologiae Plantarum 38, 119(2016)

8. M.A. Islam, S.E. Macdonald, Trees 18, 35-42(2004)

9. F. Habibzadeh, A. Sorooshzadeh, H.Pirdashti, S.A.M. Modarres-Sanavy, Australian Journal of Crop Science 7, 401-406(2013)

10. A.C. Estrada-Melo, Chao, M.S. Reid, C.Z. Jiang, Horticulture research 2, 15013(2015)

11. H. Ohkawa, N. Ohishi, K. Yagi, H. Okhawa, R. Rastogi, N. Oishi, N. Onishi, N. Qohishi, Analytical Biochemistry 95, 351-358(1979)

12. K. Sumio, A. Kozi,Plant \& Cell Physiology, 3(1989)

13. J., L., FIELDING, J., L., HALL, Journal of experimental botany, (1978)

14. S. Mueller, H.D. Riedel, W. Stremmel, Analytical Biochemistry 245, 55-60(1997)

15. G. Kaur, H.P. Singh, D.R. Batish, R.K. Kohl. Protoplasma 250, 53-62(2013)

16. G.K. Goraya, B. Asthir. Journal of Plant Biology 59, 215-222(2016)

17. HL. Yang, D Shi, J. Xiao. China Industrial Economics4,73-84 (2009)

18. M. Farooq, A. Wahid, DJ. Lee, S.A. Cheema, T. J Aziz. Agron Crop Sci 196:336-345(2020)

19. M.X. Liu, T.W. Jiang. Plant Physiol Biochem95:5764 (2015)

20. DM. Yin, S.M. Chen, F.D. Chen, Z.Y. Guan, W.M. Fang. Environ Exp Bot 68:122-130 (2010)

21. S. Bieker, U. Zentgraf. Disord 104: 53-83 (2013)

22. R.G. Alscher, J.L. Hess. Antioxidants in higher plants (1993).

23 E. Maestri, N. Klueva, C. Perrotta. Plant Molecular Biology 48: 667-681 ( 2002 )

24 P. Diaz-Vivancos, M. Faize, G. Barba-Espin. Plant Biotechnology Journal 11: 976-985(2013) 